\title{
A scientific and educational experience to engage high school students to gamma ray physics
}

\author{
C. Aramo ${ }^{a}, *$ and P. Romano $b$ \\ a INFN Sezione di Napoli, Napoli, Italy \\ ${ }^{b}$ Liceo Scientifico “Mangino”, Pagani, Italy \\ E-mail: carla.aramo@na.infn.it
}

In this paper we introduce an original scientific and educational experience conducted with Italian 16/17 years-old students attending Scientific Lyceum "Mangino" of Pagani (Italy). It was inserted in an Italian Educational Program PCTO (i.e. Percorsi per le Competenze Trasversali e per l'Orientamento), active in High Schools on a national level, with the aim to make students consolidate and expand the curricular content's knowledge via internships in private or public working environments. For this specific item, concerned CTA-PCTO (Cherenkov Telescope Array-PCTO), the students, led by a teacher and an INFN researcher, venture out into the innovative technology and the future scientific achievements of CTA, which will be the first ground-based gamma-ray observatory and the world's most sensitive and powerful gammaray instrument. All the activities carried out during the CTA-PCTO were organized as an action-research to develop an alternative, effective, and motivating approach to the study of astroparticle physics, and in particular of gamma-ray physics. In this way students benefited to the scientific and technology information of CTA and its telescopes, and they were engaged in producing different didactic items, also useful to introduce CTA technologies to other students. They created a paper model of the CTA's Large-Sized Telescope (LST), realized a crossword puzzle and write an article, and finally, they presented their work to the general public during the "European Researchers' Night" in November 2020. The mere need to report their results has produced remarkable results in their ability to write and communicate on scientific items.

37th International Cosmic Ray Conference (ICRC 2021)

July 12 th $-23 r d, 2021$

Online - Berlin, Germany

\section{*Presenter}

(C) Copyright owned by the author(s) under the terms of the Creative Commons 


\section{Introduction}

Among the science outreach activities of the Naples Section of the National Institute of Nuclear Physics (INFN-NA), the installation of the Cosmic Muon Telescope [1] in the Toledo Station of the Naples Metro in May 2014 had a strong impact on the area. The detector, consisting of $10 \mathrm{x}-\mathrm{y}$ planes of scintillator rods read by SiPM photodetectors, was built by INFN's Gran Sasso National Laboratories (LNGS), and installed in the Station by researchers from INFN-NA and the Physics Department of the Federico II University with the collaboration of engineers from the Azienda Napoletana di Mobilità (ANM). It allows the public to observe the invisible cosmic particles that arrive at a depth of forty metres in the Station (essentially muons produced in the interaction of cosmic rays with the Earth's atmosphere) through luminous LEDs that are activated when the particles pass through the telescope's scintillators. In 2016, the telescope was upgraded with the coupling to a Multimedia Totem, which provides audio-visual information on the physics of cosmic radiation, as well as real-time analysis of the data collected by the telescope, allowing the public to be shown the track and angle of origin of muons. The accumulated data are transmitted to the INFN in Naples and recorded in a special area of website [2], which secondary schools can access in order to be able to analyze them.

This initiative made it possible to launch the "A scuola di astroparticelle" (At school for astroparticles - ASA) [3] (see also the contribution by R. Colalillo in this conference) a contest for high school students, which has involved thousands of students over the last five years. Every year the students, supervised by their teachers and researchers from the proposing organizations, undertake projects on current topics in scientific research: the origins and study of the Universe, cosmic rays and gravitational waves, environmental radioactivity, methodologies in health physics, optics, nanotechnologies and quantum technologies, as well as technical aspects linked to the development of photon and particle detectors, such as the telescope in the Toledo station of the Naples metro and its Multimedia Totem from which the idea for the project originated.

All the courses of ASA are structured as the Italian Educational Program PCTO (Percorsi per le Competenze Trasversali e per l'Orientamento) [6], an active project in Italian high schools at a national level with the aim of consolidating and expanding students' curricular knowledge with internships in private or public working environments.

Each class of students, supervised by a tutor on a well-defined topic chosen by the school during the 40 hours of works, aimed to immerse in the activities that a physics researcher carries out in order to realize the results of the research and then present them at a conference in the form of a poster or oral report. Until the third edition the final event was face-to-face [4] at the end of May each year 600 students were involved in various activities: the preparation of the poster section, the opening press conference and the presentation of their work to the jury both in the poster session and in the two plenary sessions. In spite of the great effort that was necessary for the realization of their projects as well as during the two days of final activities, the students expressed great enthusiasm for all the activities.

The fourth edition refers to the 2019 call for proposals, encompasses two years of activities due to the problems caused by COVID19. In spite of many difficulties due to the pandemic and the fact that many activities that began in early 2020 in presence were then continued in online mode, many of the planned courses were completed and during the event on 25 May 2021 the students presented their work in an online event [5].

This article will present a peculiar PCTO course that involved a class of 19 Italian 16/17 yearsold students attending Scientific Lyceum "Mangino" of Pagani (Italy) on topics related to the Cherenkov Telescope Array - CTA [7].

\section{The CTA-PCTO}

During the CTA-PCTO activities, led by the students' teacher and INFN researchers, students were able to explore the intriguing extreme Universe, CTA's innovative technology and 
its coming scientific achievements. All the activities carried out during the CTA-PCTO were organized as an "action-research" to develop an alternative, effective and inspiring approach to the study of astroparticle physics and, in particular, of gamma-ray physics. With this approach, students were engaged in producing different didactic items that also would be useful to introduce CTA technologies to other students. They created a paper model of the CTA's Large-Sized Telescope [8] a crossword puzzle and an interactive Q\&A, and finally they translated a booklet, in order to better explain, successively, the gamma-ray Universe to the younger high-school students (between 10-13 years-old).

The PCTO started with face-to-face meetings but, unfortunately, due to the COVID-19 pandemic, all remaining activities continued online, triggered by the desire of the students to conclude the process. During the almost two years of activity, the students were able to engage in various activities in addition to the development of the work to be presented at the final exhibition. They started with a visit to the telescope of the Toledo Metro, participated in the International Cosmic Day ICD2020 [9], and finally took part in the European Researchers' Night "MEETmeTONIGHT " 2020 [10]. The whole experience has been reported on a website created by the students themselves [11].

\subsection{The LST paper model}

The idea behind the LST model was to create an activity that would involve children and bring them into the world of gamma rays and the instruments that detect them. What do you need to build your own Large-Sized Telescope (LST)? Three simple materials: LST printout, glue and scissors! Use the LST printout available to download [8] or draw your own design and follow this explanatory video [12] (Fig. 1) to build CTA's largest telescope at home or in the classroom. Isn't that really funny?

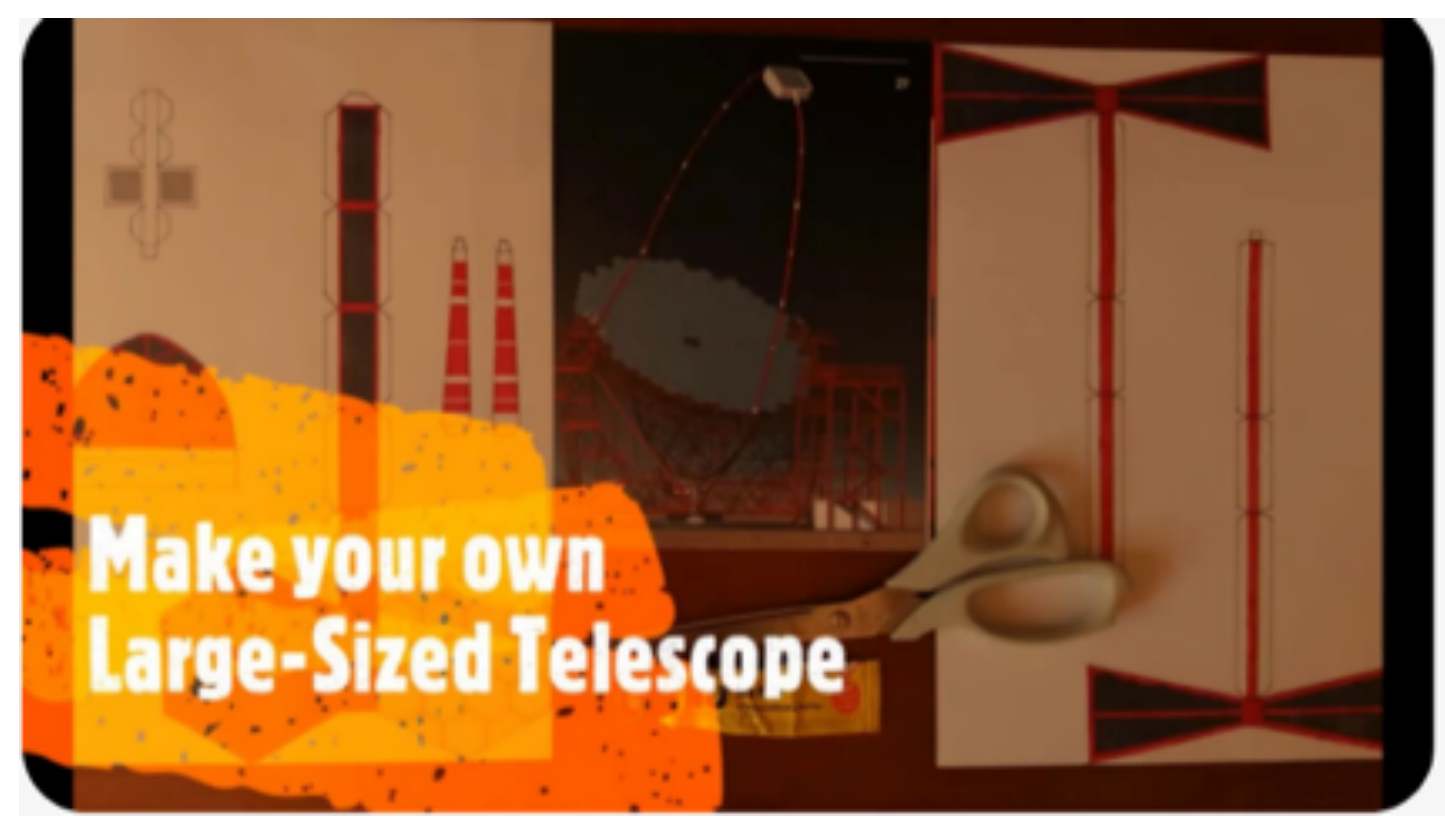

Figure 1: The LST paper model video tutorial

\subsection{The crossword puzzle and game quiz}

In addition to the video, the students also made a crossword puzzle [13] (Fig. 2) and a game quiz [14] to involve the pupils. After reading the introductory article [15] and using the glossary [16] to look up the most commonly used words in the gamma-ray Universe, it can be a lot of fun challenge themselves. 


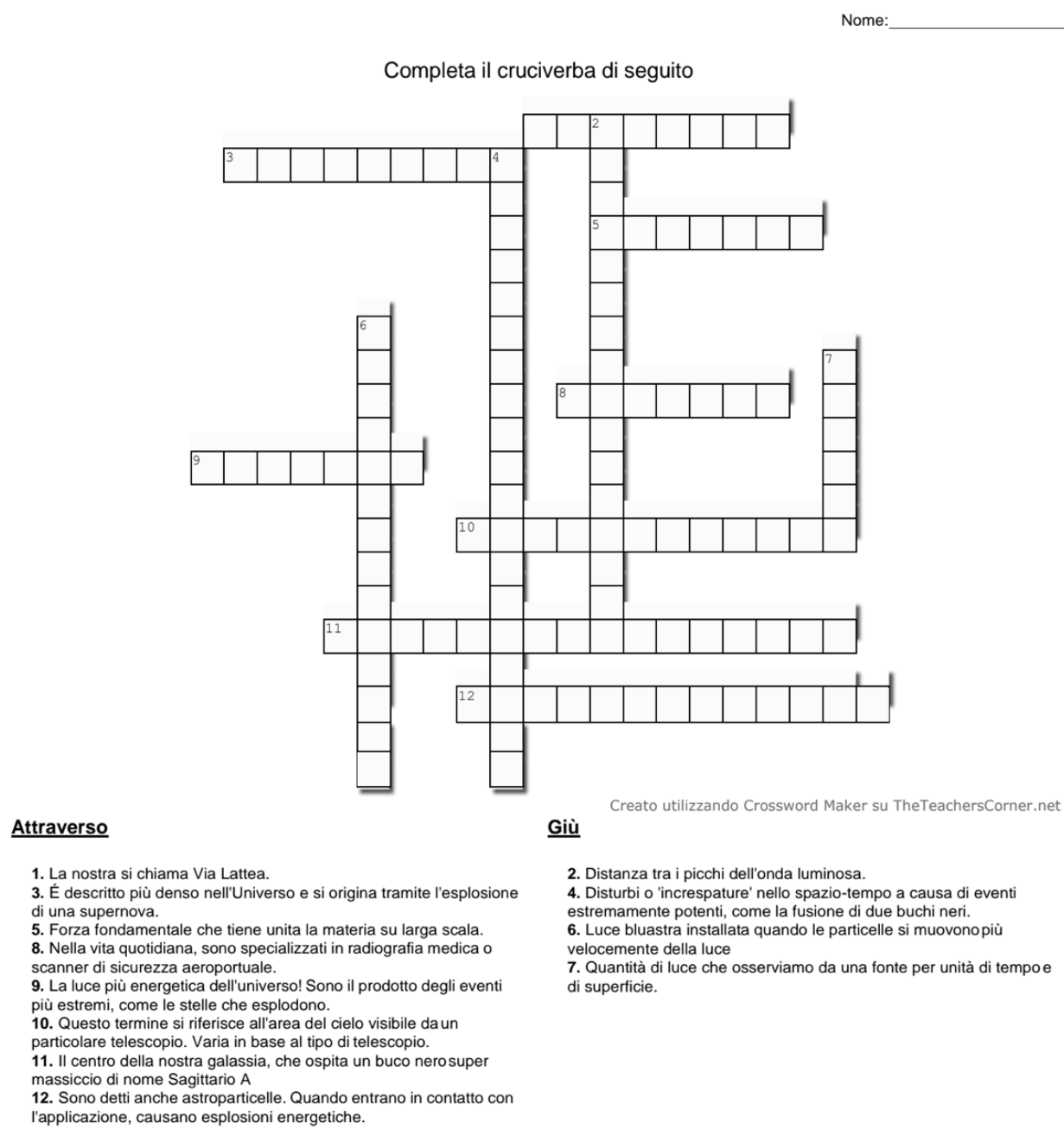

Figure 2: Crossword puzzle

\section{The ICD2020}

The International Cosmic Day (ICD) [9] is an astroparticle physics outreach event for high- school students and brings together students, schools, and various physics outreach projects from all over the world. Groups of scientists, teachers, and students meet for one day to learn about cosmic rays and perform an experiment with atmospheric muons. Students from Liceo Mangino participated in the ICD2020 following the event organized by OCRA (Outreach Cosmic Ray Activities) INFN [17] (see the contribution by S. Hemmer in this conference) as ASA is one of the local activities included in OCRA. The ICD in 2020 took place on November 4, right in the middle of the second wave of the Covid-19 pandemic. OCRA thus decided to organize an online event accessible also for students that could not be at school but were home schooling at the time During the ICD, using the "Cosmic Ray Cube" detector and its App [18], students were able to measure the muon flux as a function of angle. The proceedings of the ICD 2020 are published in a booklet and distributed to all participants in the months following the ICD. Fig 3 shows the booklet produced by the students of the Liceo Mangino with the description of the measurement results and data analyses. 


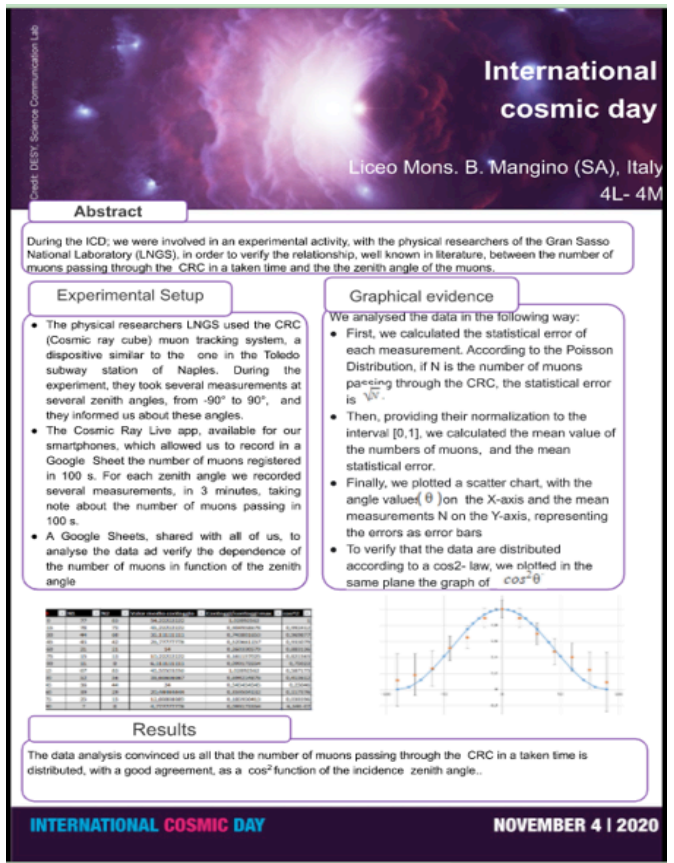

Figure 3: Booklet with the ICD2020 measurements of muon flux and data analyses

Students were already able to analyze the collected data in a laboratorial experience, but for the first time, they witnessed that this is a relevant part of a real research lab, and it has brought about a very positive impact about the importance of a good school education.

\section{MEETmETONIGHT}

MEETmeTONIGHT's main objective was to foster greater interaction between citizens and the world of science. All its activities were aimed at promoting research and its results, researchers and their profession, with a special focus on the younger generations on the one hand, and the recognition of Europe's role on the other. The intention was to show how research has an impact on our lives, how fundamental it is, how it is present in the technologies and tools we use every day, and also to demonstrate that Science is not for a small elite of people, but for everyone.

The MEETmeTONIGHT initiatives allowed participants to get to know researchers not only as scientists but also as people, showing the role of research in achieving a better and more sustainable future, as well as Europe's fundamental role in research.

The timetable also included a series of events where researchers were joined by other stakeholders, creating a sense of participation in a single community. This included the participation of Mangino High School students who presented the CTA-PCTO through the event 'Giants studying the Universe' (Fig. 4) to an online audience [19].

This was the occasion the students greatly appreciated the group work done to prepare the presentation and the speech. Indeed, for a connection problem occurring to two students at the time when it was their turn to speak, two other students immediately and properly replaced the friends in a correct way. So, they experienced how it is important that everyone had been involved in the preparation phase, Further, they became aware of the importance of a correct science communication, and realized how difficult is to prepare a good speech to do in an allotted time. 


\section{INFN SEZ. NAPOLI \\ LICEO SCIENTIFICO \\ "MONS. B. MANGINO" PAGANI \\ "A SCUOLA DI ASTROPARTICELLE" I GIGANTI CHE STUDIANO L'UNIVERSO}

28/11/2020 4L-4M

Tutor: dr.ssa Carla Aramo

Tutor scolastico : prof.ssa Piera Romano
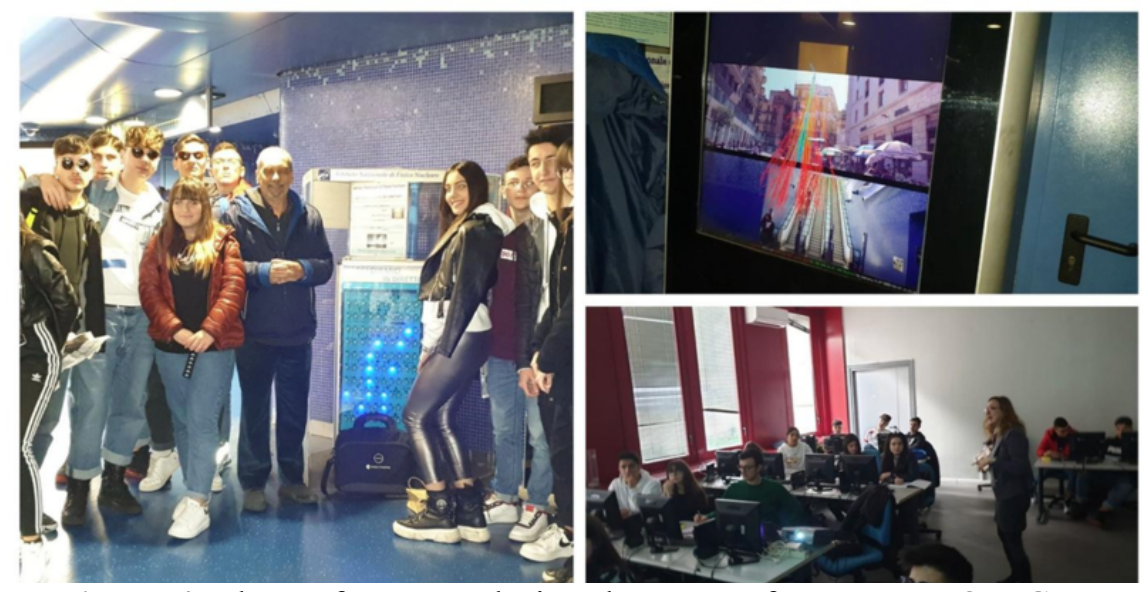

Figure 4: The performance during the event of MEETmeTONIGHT

\section{The "A scuola di astroparticelle" contest}

On 25 May, more than 300 students from Campania's high schools met online, together with their teachers and 12 tutors, to present their work for ASA, a project promoted by the National Institute of Nuclear Physics (INFN), in collaboration with the Department of Physics "Ettore Pancini" of the Federico II University of Naples, the SPIN, ISASI and INO Institutes of the National Research Council (CNR) and, from this edition, the Capodimonte Astronomical Observatory of the National Institute of Astrophysics (INAF). The fourth edition was marked by the particular conditions due to the pandemic and many activities, started in presence in 2019 and transformed into online activities, continued also during the school year 2020/21, incorporating two years of PCTO.

The initiative saw the involvement of 10 schools in Campania, carrying out 18 projects on current topics in scientific research: the origins and study of the Universe, cosmic rays and optics, environmental radioactivity, radon and scientific communication, as well as technical aspects related to the development of photon and particle detectors. The more than 800 hours of PCTO were spent on introductory seminars, laboratory activities and data analysis on a welldefined topic chosen by the school and, with the support of the tutors from the promoting organizations, it was possible to guide the students through the activities that a researcher carries out in order to carry out his or her research, and then present it during a workshop. The result of these two years of activity, presented by the students themselves on the Zoom platform (Fig. 5), who took turns in displaying their work during the morning, was assessed by the judging panel, with the arduous task of selecting the winning work for the fourth edition. The Liceo Mangino students decided to present their work using slides (Fig.6), but they also organized a website [20], using Google Sites. The website was considered a useful tool to collect and illustrate all the activities carried out in the CTA-PCTO, and the design work, done by the students with the help of their teacher, contributed to also improve their digital skills, above the communication one. Having actively participated in MeetMeTonight greatly contributed to the preparation of this final phase: students, in fact, were less anxious and more competitive. They were all very professional and competent, taking all the other students on the platform on a fascinating journey into the world of gamma rays. 


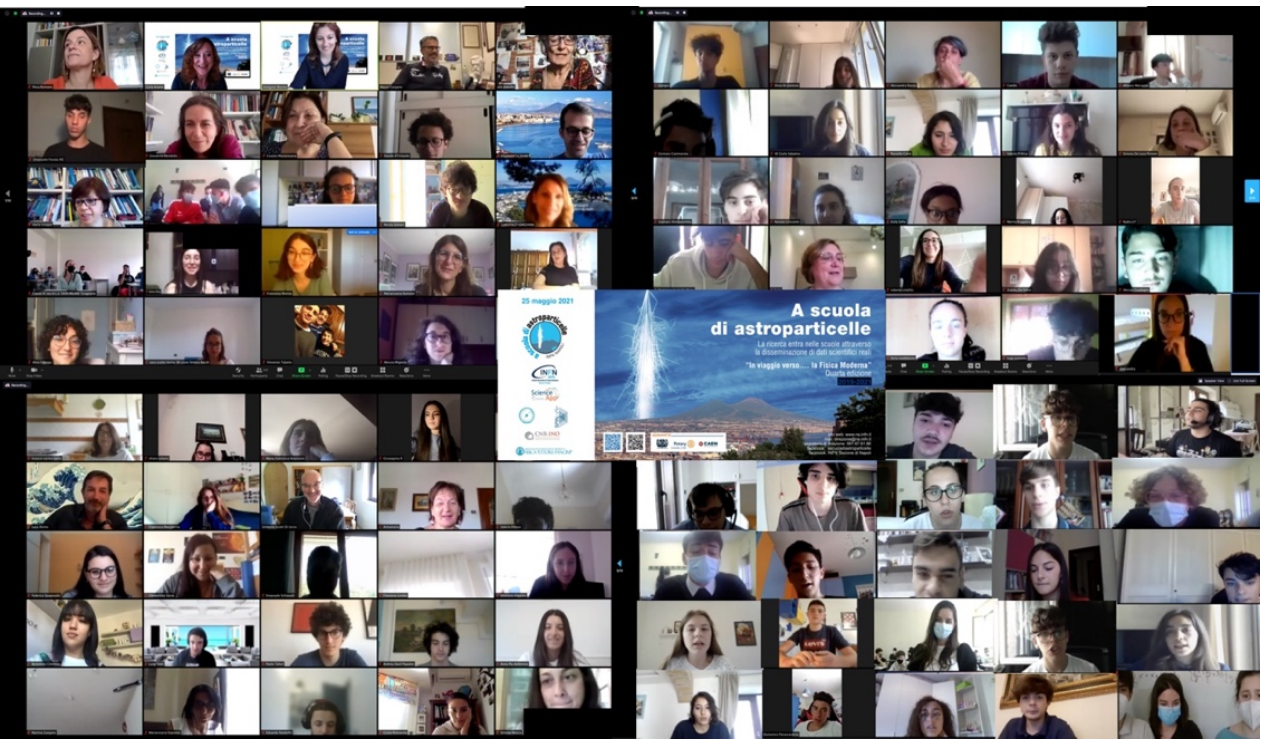

Figure 5: Students, teachers and tutors in Zoom connection during the event on 25 May.

\section{Conclusions}

The CTA-PCTO was greatly received and appreciated by the students of Liceo Mangino and their teacher: the program was organized combining the theoretical with the laboratory part. The visit to the metro station Toledo had a great impact because, on the one hand, the students were able to see how scientific instruments can be installed even in places where people usually stay, and on the other hand, the view of the telescope stimulated the curiosity of students who had not yet studied modern physics in their curriculum. Moreover, the request to become animators for younger pupils themselves gave importance to the design of challenging activities, and participation in external events clarified some fundamental aspects of research work, in physics, but in scientific disciplines in general. Indeed, beyond the disciplinary competences, there were important transversal skills that have been improved throughout the proposed formative path. The need to tell a wide audience about their training experience and to arrange challenging activities, such as the crossword puzzle, the paper model and the quiz, led to a reversal of roles, so that students, often used to being assessed by the teacher, were instead asked to self-evaluate their work in order to improve it and present it to others, both on the website and during the events in which they participated. Finally, the CTA collaboration also greatly appreciated the work carried out, devoting an article in the experiment's newsletters [21].
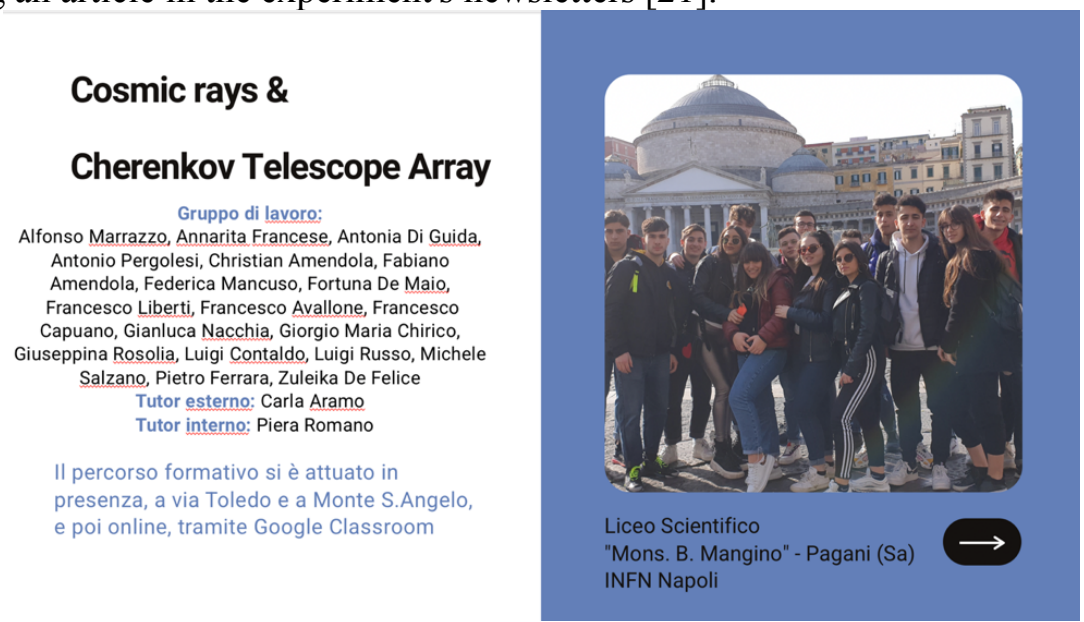

Figure 6: The introductory slide of the Liceo Mangino students' presentation 


\section{References}

[1] F. Arneodo et al., Muon tracking system with Silicon Photomultipliers, NIMA 799 (2015) 166-171

[2] http://people.na.infn.it/ totem/Eventi/

[3] https://www.facebook.com/ascuoladiastroparticelle

[4] https://agenda.infn.it/event/19242/

[5] https://agenda.infn.it/event/26846/overview

[6] https://www.miur.gov.it/documents/20182/1306025/Linee+guida+PCTO+con+allegati.pdf

[7] https://www.cta-observatory.org/, https://www.worldscientific.com/worldscibooks/10.1142/10986

[8] https://www.cta-observatory.org/outreach-education/cta-for-educators/

[9] https://icd.desy.de/

[10] https://www.meetmetonight.it/

[11] https://sites.google.com/liceomangino.it/pcto-mangino-infn-cosmic-rays/home?authuser=0

[12] https://www.youtube.com/watch?v=XJIvw-BpRUg\&t=13s

[13] https://drive.google.com/file/d/1sLY7A3lb6fOFgwAkIrc7HqdznYABIVIj/view

[14] https://docs.google.com/forms/d/e/1FAIpQLSeY5YWoBHvVLQDQrVKe7bG-0hvdMLJaVf5J3NOzA28Fy6Bgw/viewform

[15] https://www.flipbookpdf.net/web/site/92884d86f924c4a41b1cea3e7dc07cff374803da202105.pdf.ht $\underline{\mathrm{ml}}$

[16] https://www.flipbookpdf.net/web/site/5b313e703f58c0725ec9db1484d5b60e15f5d9ee202105.pdf.ht $\underline{\mathrm{ml}}$

[17] https://web.infn.it/OCRA/international-cosmic-day/international-cosmic-day-2020/

[18] https://web.infn.it/OCRA/misura-dei-muoni-in-funzione-dellangolo-di-zenith/

[19] https://www.lenuvole.it/scienza/meetmetonight-28-novembre-mattina/

[20] https://agenda.infn.it/event/26846/contributions/137550/

[21] https://mailchi.mp/7ad7b9e94efa/cta-newsletter-may2021-english\#INFN 